\title{
Tribute to Professor Eduardo Argentino Sosa
}

\section{Denise Hachul ${ }^{1}$ - Mauricio Scanavacca ${ }^{1}$}

Published online: 13 July 2020

(C) Springer Science+Business Media, LLC, part of Springer Nature 2020

January 25, 1942-June 20, 2020

On June 20, Brazilian cardiology lost one of its greatest icons.

Eduardo Argentino Sosa was born in Rosario, Argentina. After finishing the medical school, he chose the Clinics Hospital of the University of São Paulo, School of Medicine (HC-FMUSP), to carry out his specialization in cardiology and Brazil as his country of citizenship where he lived from 1968 until his last day of life.

With his strong, self-taught, and visionary spirit, in the mid-1970s and in partnership with his compatriot and cardiovascular surgeon, Prof. Miguel Barbero Marcial, he carried out the first intracardiac electrophysiological mappings in Brazilian territory, during open chest surgery, using equipment produced at the hospital's Bioengineering Service.

In the early 1980s, after the inauguration of the Heart Institute of FMUSP, he was assigned to develop a Cardiac Arrhythmias Service. Surgical ablations of Wolff-ParkinsonWhite syndrome and ventricular tachycardias refractory to clinical treatment, especially related to Chagas disease, which is quite prevalent in our country, started to be regularly performed in the institution.

In the mid-1980s, electrophysiological mappings began to be executed in the hemodynamics service, worldwide. The treatment of arrhythmias by electro-fulguration, followed by radiofrequency ablation using catheters, was then introduced in the clinical practice of our hospital.

With the incorporation of electronic evaluation and programming of implantable devices, InCor's arrhythmia service grows into the Clinical Arrhythmia and Pacemaker Unit, and Dr. Sosa integrated his disciples and post-graduate students: Mauricio Scanavacca at the Interventional Electrophysiology;

Mauricio Scanavacca

mauricio.scanavacca@ incor.usp.br;

mauricio.scanavacca@gmail.com

1 Arrhythmia Unit, Heart Institute (InCor), University of São Paulo Paulo - School of Medicine, Av Dr Eneas Carvalho de Aguiar, 44 São Paulo 05403-000 Brazil
Martino Martinelli Filho at the Pacemaker Clinic; and a few years later, in 1990, Denise Hachul at the Syncope Clinic and Francisco Darrieux at the Didactic Ambulatory. And so, we lived and worked together for the past three decades.

As long as the service was expanding, a new generation of brilliant clinical arrhythmologists and electrophysiologists has been gradually incorporated in the service. Due to his strong personality and great leadership, Dr. Sosa transformed the InCor's Arrhythmias Unit into a Brazilian and Latin American reference center. The staff under his command was responsible for the education and training of dozens of young Brazilian and Latin American cardiologists over more than 30 years.

Although having many original articles published, especially in Latin American Journals, his team was recognized worldwide in 1995, due to the development of the innovative technique of percutaneous epicardial ablation, motivated by the difficulties and inefficacy the endocardial ablation of Chagas' ventricular tachycardia, a great challenge for the Latin American electrophysiological community. With this recognition, countless of electrophysiologists around the world began to attend InCor for training in the new technique, today indicated for several other clinical situations.

In addition to his outstanding professional and academic performance, Dr. Sosa was one of the founders of the Department of Cardiac Arrhythmias and Electrophysiology of the Brazilian Society of Cardiology, more than 30 years ago, which gave rise to the Brazilian Society of Cardiac Arrhythmias (SOBRAC) currently counting with more than 1000 members.

A man of many talents, cheerful, and irreverent, Dr. Sosa was also always present at the festive celebrations with his staff, doctoral students, and fellows, in which we used to play "argentine boleros" together on the piano and the guitar.

Despite having been ill for about 10 years, he continued to go to the hospital, where he remained studying and discussing clinical cases with the staff and fellows. The loss of our daily contact with Dr. Sosa occurred in mid-2016, when the physical limitation due to the chronic illness was accentuated and 
he definitely retired to family life, as he wished. In the last 4 years, we had to learn to work and live without his strong presence and charismatic personality and his quick thinking and brilliant comments with that Spanish accent-which he made sure never to miss - and always accompanied by a wide smile on his face.

Professor Sosa died as a result of his chronic disease. Married, he had a daughter, a son, and two grandchildren, one of them named Eduardo.

Dr. Sosa, we will miss you, honor your legacy, and you will always have our admiration and recognition.

Denise Hachul

Mauricio Scanavacca

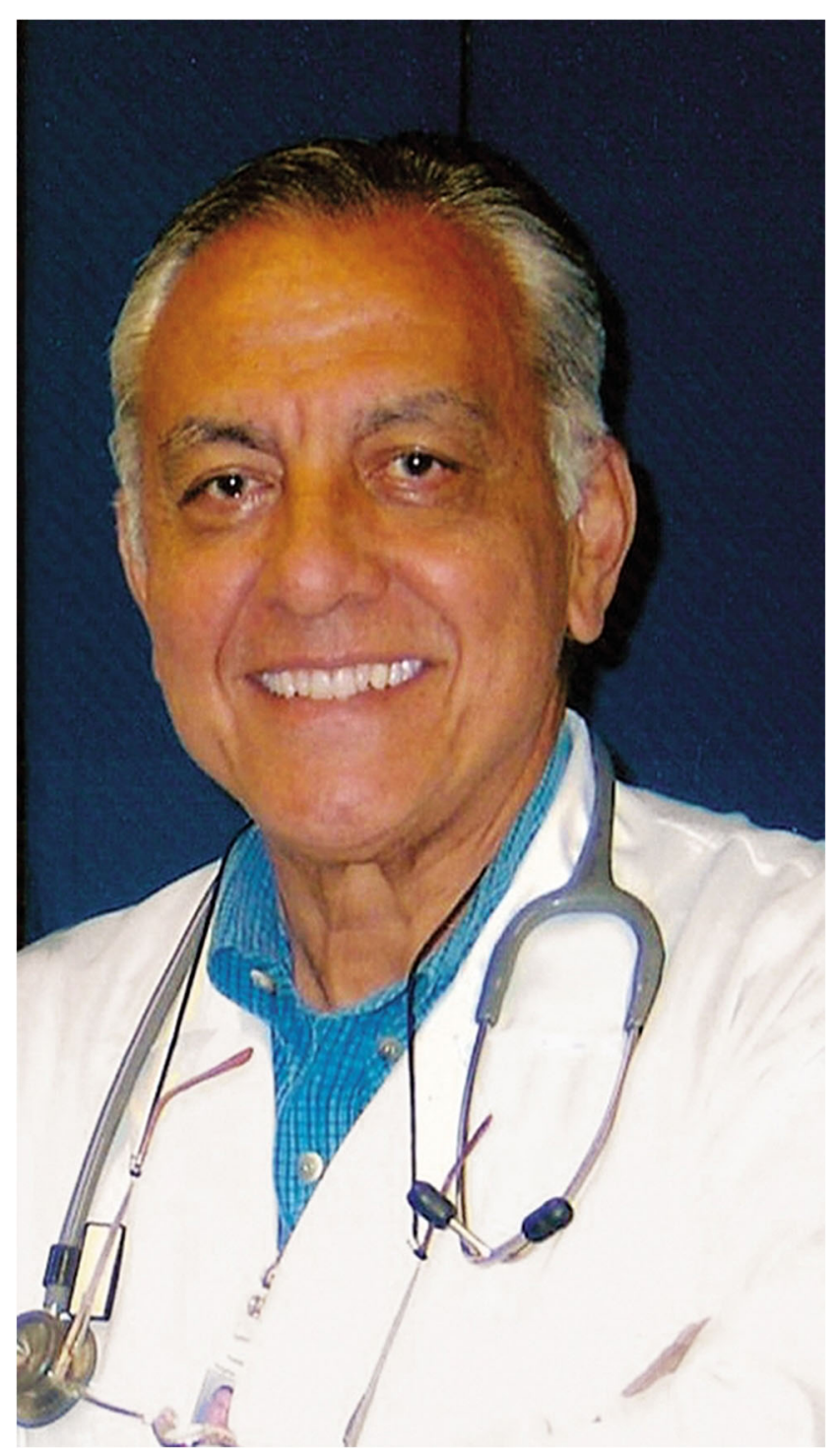

Publisher's note Springer Nature remains neutral with regard to jurisdictional claims in published maps and institutional affiliations. 